\title{
Patient-centered care during the last year of life: adaptation and validation of the German PACIC short form for bereaved persons as proxies (PACIC-S9-proxy)
}

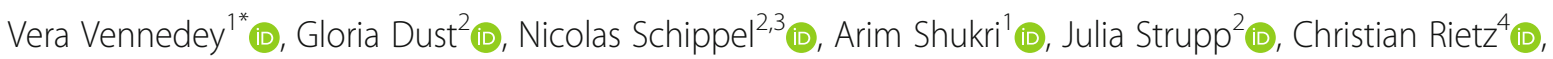
Raymond Voltz ${ }^{2,5,6,7}$ and Stephanie Stock ${ }^{1}$ (i)

\begin{abstract}
Background: Providing patient-centered care (PCC) during the last year of life (LYOL) can be challenging due to the complexity of the patients' medical, social and psychological needs, especially in case of chronic illnesses. Assessing PCC can be helpful in identifying areas for improvements. Since not all patients can be surveyed, a questionnaire for proxy informants was developed in order to retrospectively assess patient-centeredness in care during the whole LYOL. This study aimed to evaluate the feasibility and validity of an adapted version of the German Patient Assessment of Chronic Illness Care (PACIC) for surveying bereaved persons in order to assess PCC during the decedents' LYOL.

Methods: The German PACIC short form (11 items) was adapted to a nine-item version for surveying bereaved persons on the decedent's LYOL (PACIC-S9-Proxy). Items were rated on a five-point Likert scale. The PACIC adaptation and validation was part of a cross-sectional survey in the region of Cologne. Participants were recruited through self-selection and active recruitment by practice partners. Sociodemographic characteristics and missing data were analyzed using descriptive statistics. An exploratory factor analysis was conducted in order to assess the structure of the PACIC-S9-Proxy. Internal consistency was estimated using Cronbach's alpha.

Results: Of the 351 informants who participated in the survey, 230 (65.52\%) considered their decedent to have suffered from chronic illness prior to death. 193 of these informants (83.91\%) completed $\geq 5$ items of the questionnaire and were included in the analysis. The least answered item was item (74.09\%) was item 4 (encouragement to group \& classes for coping). The most frequently answered item (96.89\%) was item 2 (satisfaction with care organization). Informants rated the item" Given a copy of their treatment plan" highest (mean 3.96), whereas "encouragement to get to a specific group or class to cope with the condition" (mean 1.74) was rated lowest. Cronbach's alpha was 0.84. A unidimensional structure of the questionnaire was found (Kaiser-MeyerOlkin 0.86, Bartlett's test for sphericity $p<0.001$ ), with items' factor loadings ranging from 0.46 to 0.82 .

(Continued on next page)
\end{abstract}

\footnotetext{
* Correspondence: vera.vennedey@uk-koeln.de

'Institute for Health Economics and Clinical Epidemiology, Gleueler Straße 176-178, 50935 Cologne, Germany

Full list of author information is available at the end of the article
}

(c) The Author(s). 2020 Open Access This article is licensed under a Creative Commons Attribution 4.0 International License, which permits use, sharing, adaptation, distribution and reproduction in any medium or format, as long as you give appropriate credit to the original author(s) and the source, provide a link to the Creative Commons licence, and indicate if changes were made. The images or other third party material in this article are included in the article's Creative Commons licence, unless indicated otherwise in a credit line to the material. If material is not included in the article's Creative Commons licence and your intended use is not permitted by statutory regulation or exceeds the permitted use, you will need to obtain permission directly from the copyright holder. To view a copy of this licence, visit http://creativecommons.org/licenses/by/4.0/ The Creative Commons Public Domain Dedication waiver (http://creativecommons.org/publicdomain/zero/1.0/) applies to the data made available in this article, unless otherwise stated in a credit line to the data. 
(Continued from previous page)

Conclusions: The nine-item questionnaire can be used as efficient tool for assessing PCC during the LYOL retrospectively and by proxies.

Trial registration: The study was registered in the German Clinical Trials Register (DRKS00011925) on 13 June 2017.

Keywords: Last year of life, End-of-life, Patient-centered care, Patient-centered care, Questionnaire, Cross sectional study, Validity, Factor analysis, PACIC

\section{Background}

Care for chronically ill multimorbid patients is a major challenge for many healthcare systems. Especially during the last year of life (LYOL) patients experience a high burden of physical symptoms and psychosocial needs which need to be addressed. At the same time, the overall use of healthcare services usually increases during the LYOL leading to multiple transitions between care settings [1]. (e.g. home to hospital; from one specialist to another, hospital to nursing home) [2, 3]. If these transitions are not managed properly, patients will experience disruptions and failures in coordination of care, which, at the worst-case scenario, can lead to preventable readmissions and patient burden. Patients and their relatives therefore expect that end-of-life care to be characterized by a patient-centered approach in the sense described by Balint as considering a patient as a "unique humanbeing" [4] (p. 269) instead of regarding them purely as an illness to treat. Later, the Institute of Medicine (IOM) established the widely accepted definition of PCC as "care that is respectful of and responsive to individual patient preferences, needs, and values and ensuring that patient values guide all clinical decisions" (p. 5) [5]. Patient-centeredness in care is also considered a core attribute of palliative care, being reflected in the second guiding principle of the German Charter of Care for severely ill and dying persons in Germany [6]. Important features of PCC during the LYOL include informing patients about their options and treatments, involving them in care, coordinating care, delivering interdisciplinary team based care, and providing physical and emotional support [7-14]. PCC thus aims to support patients' autonomy and their active involvement in the choice of treatment, and to alleviate caregiver burden. Several studies report positive associations between patient-centeredness in care for elderly, multimorbid or palliative patients and their health outcomes and/or satisfaction with their care $[15,16]$.

Patients are often severely ill during their LYOL and suffer from physical or cognitive constraints, which sometimes make it difficult to ask the patients themselves about their needs, values and preferences for care are. As such, clinicians and researchers often have to rely on the opinions of relatives, friends or other contact persons with a personal or occupational attachment to the patient. Additionally, as this study aimed to assess the patient-centeredness throughout the whole LYOL, retrospectively surveying friends and relatives was necessary. Several studies used proxy informant studies and investigated the feasibility of proxy-informants on topics related to the LYOL $[17,18]$. A review of such studies found proxy answers to be reliable in the context of quality of healthcare services and more objective reporting of symptoms [19]. The available studies mainly focus on experiences during the LYOL in specific settings such as in long-term or palliative care setting, acute care or the quality of care in general $[17,20]$. None of the instruments specifically addresses patient-centeredness during the LYOL. One survey instrument commonly used to assess patient-centeredness is the Patient Assessment of Chronic Illness Care (PACIC) [20]. However, this instrument is only validated for surveying patients. As the LYOL can only be determined retrospectively, it is necessary to survey proxy informants is necessary. To the best of our knowledge, none of the questionnaires currently available can be used to retrospectively assess the level of patient-centeredness of care during the LYOL. This study aimed to evaluate the feasibility and validity of an adapted PACIC short form in surveying bereaved persons regarding the perception of patientcenteredness in the care of the decedents.

\section{Methods \\ Setting}

This project was conducted within the Cologne Research and Development Network (CoRe-Net), which consists of scientists, patient organizations, HSCOs, municipality representatives and other stakeholders. The data collection for this study took place within the research project LYOL-C (Last Year of Life - Cologne), which is one of three initial projects affiliated with CoRe-Net [21, 22]. CoRe-Net members participated in developing ideas on the conducting of the study. A multi-item and multiscale questionnaire for bereaved persons was set up to assess the process and experience of care during the LYOL of the deceased person. The questionnaire included socio-demographic questions related to the informant and decedent, a chronological survey of places 
of care within the LYOL, wishes and experiences of in the LYOL, a recently developed German version of the VOICES [23], and a newly adapted version of the German PACIC short form [24] - named the PACICS9-Proxy. The original PACIC and its short form's psychometric properties have been analyzed previously [24-26]. This paper reports on the adaptation and validation of the PACIC-S9-Proxy, and the level of patientcenteredness experienced in the LYOL. The results of the VOICES data are presented elsewhere [27].

\section{Questionnaire adaptation}

For this study, the German short version of the PACIC was adapted [24-26]. First, the answer scale of the PACI $\mathrm{C}$ short form (percentages) was switched back to the format of the answer scale from the original German PACI $\mathrm{C}$ long version. This scale is easier to understand, since answers can be provided on a five-point scale corresponding to "almost never" $(=1)$, "generally not", "sometimes", "most of the time", and "almost always" (=5). To prevent the informants from choosing random answers, the answer category "unable to rate" was included. This category ensures that only those informants who feel able to provide valid data are included [28]. This answer category also facilitates an analysis of which aspects informants might be less able to provide information for with regard to patient-centeredness. As a second adaptation, items three (being supported in setting goals for healthier lifestyle) and six (being asked about health behaviour e.g. smoking) of the German PACIC short form were excluded since they were not deemed particularly important in care during the LYOL. Lastly, the phrasing of items was adapted to address the bereaved relatives rather than the decedents e.g. the item "How often was I satisfied that my care was well organized?" was adapted to "How often was your loved one satisfied that his / her care was well organized?" The adapted version was deemed comprehensible and feasible in eight cognitive pre-tests involving persons from the target group and no further adaptation appeared to be necessary. An English version of the questionnaire is provided in supplementary file 1 . The original German questionnaire is available upon request.

\section{Participants, recruitment \& data collection}

Informants were eligible for study participation if they had lost a person close to them (e.g. friend, relative or partner) within the last 12 months, and if this deceased person lived in the region of Cologne and did not die due to an accident or killing. Both, the study participant and the decedent had to be at least 18 years old. For data protection reasons, the eligibility criteria were selfassessed and not verified by registry offices or similar bodies. Around 100 practice partners participated in the recruitment, including general practitioners, nursing homes, outpatient nursing services, hospitals, working groups in palliative and hospice care, morticians, health insurance companies, self-help groups, churches, public health services, community colleges, municipal representatives for senior citizens in Cologne, and civic centers. Two strategies were used for the recruitment of participants: i) Direct distribution of questionnaires by cooperating practice partners, either in person or by mail using the details in the patients'/ clients' records. ii) Selfselection via newspaper articles or flyers and posters, which were also placed in the practice partners' institutions. Potential participants were asked to contact the study team to receive a questionnaire by regular mail. People who requested a questionnaire, but did not return it received one reminder. Data were collected between November 2017 and August 2018 in a cross sectional study.

\section{Data analysis}

All analyses were conducted using IBM SPSS Statistics for Windows, version 25 (IBM Corp., Armonk, N.Y., USA). All data was pseudonymized for the analyses. Socio-demographic data were analysed using descriptive statistics. All returned PACIC-S9-Proxy questionnaires with at least five out of nine items from completed with an answer category ranging from "almost never" $(=1)$ to "almost always" (=5) were included in the analysis. Means and standard deviations were calculated for each item. Items which participants felt unable to rate and missing values were imputed using the mean values for the respective items from the overall sample. As in the original PACIC versions, the answer scale was converted during the analysis into a cardinal scale, where 1 corresponds to the worst rating of an item and 5 to the best rating. The internal consistency of the questionnaire was estimated using Cronbach's alpha, which can range from 0 to 1 where 0 corresponds to no correlation among the items and 1 to perfect correlation. An exploratory factor analysis was performed using principal factor analysis (eigenvalue $>1$, varimax rotation). The Kaiser-MeyerOlkin (KMO) criterion of sampling adequacy was used and Bartlett's test of sphericity was conducted. An alpha level of $P<0.05$ was applied in significance tests. In sensitivity analyses only questionnaires in which all nine items had been answered were considered.

\section{Results}

\section{Participant characteristics}

Out of the 351 informants who answered the questionnaire, $230(65.53 \%)$ stated that the deceased person had suffered from a chronic illness. Of this number, 193 (83.91\%) felt able to provide rating and completed at least five items of the PACIC-S9-Proxy with an answer 
ranging from "almost never" (=1) to "almost always" (= $5)$, and were therefore included in the analysis. The majority of the informants were spouses $(44.04 \%)$ or children (40.41\%) of the decedent, and had an average age of 69 (range: 22-87). The decedents were 79 years on average and the majority suffered from oncological conditions $(60.10 \%)$ and various cardiovascular diseases (51.81\%). Further socio-demographic characteristics can be found in Table 1 .

\section{Results of questionnaire evaluation}

The mean ratings and distributions of items are displayed in Table 2. On average, informants rated item 3 (given medication plan) highest (3.69 of 5). In contrast, informants stated that the decedent was "generally not" (1.74 of 5, Item 4) encouraged to seek groups or classes for coping with the illness. This item was also the item for which informants most often considered themselves unable to provide a rating (24.4\%). Item 2 (satisfaction with well-organized care) was answered most often (96.1\%). Informants stated that on average decedents were moderately to rather satisfied (3.52 out of 5 ) with the medical care they received.

Table 3 displays the results of the factor analysis for the PACIC-S9-Proxy. A one-dimensional structure of the questionnaire was observed in the exploratory factor analysis where the Eigenvalue drops to 0.97 at the second factor (see Fig. 1).

Overall, the analysis shows an explained variance of $45.12 \%$, a KMO of 0.86 , and a significant Barlett's test of sphericity with $p<0.001$. The internal consistency estimated using Cronbach's alpha was 0.84 . The factor loadings are displayed in Table 3 and ranged from 0.46 for item 4 to 0.82 for item 6 .

A sensitivity analysis (not shown) including only those informants who completed all items of the PACIC-S9Proxy $(N=94)$ revealed comparable results to those observed in the main analysis.

\section{Discussion}

This study evaluated the validity of an adapted PACI C short form questionnaire for surveying proxy informants on the level of patient-centeredness experienced in care during the decedents' LYOL. The onefactor structure of the original instrument was also observed in this analysis of the adapted version. The instrument can be rated as having good internal consistency with a Cronbach's alpha of 0.84. Informants rated the item" given a copy of their treatment plan" highest, while "encouragement to get to a specific group or class to cope with the condition" was rated lowest. The highest and lowest rated items seem to reasonably represent care practices in Germany. Since 2016, patients who are receiving three or more types of medication for treatment are legally entitled to receive a structured and detailed medication plan (Section 31a Volume 5 of the German Social Code Book [SGB V] [29]. As patients in their LYOL are often multi-morbid and therefore usually fulfil the criterion of receiving three or more types of medication [25], it is plausible that this item reflects the most frequently implemented aspect of PCC. "Encouragement to get to a specific group or class to cope with the condition" might have been the lowest rated item due to healthcare providers considering the decedents physically, mentally or emotionally incapable of participating in such groups.

In addition to the medication plan, there is also a legal basis requiring structured care management in relation to transitions from hospitals to other care organizations, or to the patient's home. Since October 2017, patients within the German social health insurance system are entitled to structured discharge management. Despite this, the item satisfaction with the organization of care was rated low. Since data collection only started in November 2017 the discharge management might not have been implemented to a high degree in all organizations. Moreover, each additional transition between healthcare settings, increases the chances of organizational problems in the transitions. Since transitions from one care organization to another are common in the LYOL, this might explain the low degree of satisfaction. Other studies from the perspective of informal caregivers have also observed problems in discharge management and unorganized transitions [30]. Future surveys using the same instrument may observe improvements in discharge management. None of the other items are addressed specifically in laws or regulations, so their level of implementation is therefore up to the individual providers.

As with the widely applied original long version of the PACIC we assume that, if translated appropriately, the PACIC-S9-Proxy can be applied in other countries [31, 32]. The concept of PCC is accepted internationally and many healthcare systems and providers strive for its implementation, especially in Europe and Northern America. As such, the items can also be considered relevant to other countries. Nevertheless, we expect scores for individual items to differ across countries due to different regulations, processes or traditions in healthcare provision, such as obligatory medication plans or availability of palliative care services.

\section{Strengths and limitations}

The broad recruitment strategy and inclusion of informants with different relationships to the decedents is a strength of this study, as is it reporting on decedents 
Table 1 Informant and decedent characteristics ( $N=193)$

\begin{tabular}{|c|c|c|c|}
\hline & Characteristic & $\mathrm{n}$ & $\%$ \\
\hline \multirow[t]{18}{*}{ Informant } & Age (average 69 years) & & \\
\hline & $18-29$ years & 1 & $(0.52)$ \\
\hline & $30-49$ years & 26 & (13.47) \\
\hline & 50-64 years & 91 & $(47.15)$ \\
\hline & $65-79$ years & 63 & (32.64) \\
\hline & $80+$ years & 12 & $(6.22)$ \\
\hline & Sex & & \\
\hline & Male & 45 & (23.31) \\
\hline & Female & 148 & (76.68) \\
\hline & Relationship to decedent & & \\
\hline & Spouse & 85 & $(44.04)$ \\
\hline & Son/daughter & 78 & $(40.41)$ \\
\hline & Sibling & 6 & (3.11) \\
\hline & Son-in-law/daughter-in-law & 3 & (1.55) \\
\hline & Parent & 2 & $(1.04)$ \\
\hline & Other relationship & 7 & (3.63) \\
\hline & Friend & 8 & $(4.15)$ \\
\hline & Other & 4 & $(2.07)$ \\
\hline \multirow[t]{28}{*}{ Decedent } & Age at death (average 79 years) & & \\
\hline & $18-29$ years & 1 & $(0.51)$ \\
\hline & 30-49 years & 2 & $(1.04)$ \\
\hline & $50-64$ years & 44 & $(22.80)$ \\
\hline & $65-79$ years & 62 & (32.12) \\
\hline & $80+$ years & 84 & $(43.52)$ \\
\hline & Sex & & \\
\hline & Male & 96 & $(49.74)$ \\
\hline & Female & 97 & $(50.26)$ \\
\hline & German citizenship & & \\
\hline & Yes & 187 & $(96.89)$ \\
\hline & No & 6 & (3.11) \\
\hline & Family situation $^{\mathrm{a}}$ & & \\
\hline & Had a partner & 94 & $(48.7)$ \\
\hline & Lived together with partner & 70 & $(36.27)$ \\
\hline & Had children & 97 & $(50.26)$ \\
\hline & Lived together with children & 20 & (10.36) \\
\hline & Lived together with someone else & 11 & (5.70) \\
\hline & Lived alone & 64 & (33.16) \\
\hline & Illnesses in the last year of life $\mathrm{e}^{\mathrm{a}}$ & & \\
\hline & Cancer & 116 & $(60.10)$ \\
\hline & Cardiovascular disease & 100 & $(51.81)$ \\
\hline & Neuro-psychological disease & 93 & $(48.19)$ \\
\hline & Disease of the respiratory system & 89 & $(46.11)$ \\
\hline & Liver or kidney disease & 39 & (20.21) \\
\hline & Diabetes mellitus & 31 & $(16.06)$ \\
\hline & Other & 54 & (27.98) \\
\hline & a Multiple responses were possible. & & \\
\hline
\end{tabular}


Table 2 Item frequencies \& means $(N=193)$

\begin{tabular}{|c|c|c|c|c|c|c|c|c|c|c|}
\hline \multicolumn{2}{|r|}{$\begin{array}{l}\text { Item } \\
\text { What was your relative's experience of the care } \\
\text { they received for their chronic illness during } \\
\text { the last year of life? }\end{array}$} & \multirow{2}{*}{$\begin{array}{l}\text { almost } \\
\text { never } \\
\text { n (\%) }\end{array}$} & \multirow{2}{*}{$\begin{array}{l}\text { generally } \\
\text { not } \\
\text { n (\%) } \\
26(13.47)\end{array}$} & \multirow{2}{*}{$\begin{array}{l}\text { sometimes } \\
\text { n (\%) }\end{array}$} & \multirow{2}{*}{$\begin{array}{l}\text { most of } \\
\text { the } \\
\text { time } \\
\mathbf{n}(\%) \\
29 \\
(15.03)\end{array}$} & \multirow{2}{*}{$\begin{array}{l}\text { almost } \\
\text { always } \\
\text { n (\%) } \\
40(20.73)\end{array}$} & \multirow{2}{*}{$\begin{array}{l}\text { unable } \\
\text { to rate } \\
\text { n (\%) } \\
20 \\
(10.36)\end{array}$} & \multirow{2}{*}{$\begin{array}{l}\text { Missing } \\
\text { n (\%) } \\
4(2.07)\end{array}$} & \multirow{2}{*}{$\begin{array}{l}\begin{array}{l}\text { Mean } \\
\text { rating }^{a}\end{array} \\
2.94\end{array}$} & \multirow{2}{*}{$\begin{array}{l}\text { SD } \\
\\
1.45\end{array}$} \\
\hline 1 & $\begin{array}{l}\ldots \text { were they given choices about treatment } \\
\text { to think about. }\end{array}$ & & & & & & & & & \\
\hline 2 & $\begin{array}{l}\ldots \text { were they satisfied that their care was well } \\
\text { organized. }\end{array}$ & $10(5.18)$ & 25 (12.95) & $14(7.25)$ & $\begin{array}{l}75 \\
(38.86)\end{array}$ & 63 (32.64) & $6(3.11)$ & & 3.83 & 1.17 \\
\hline 3 & $\begin{array}{l}\text {... were they given a copy of their treatment } \\
\text { plan. }\end{array}$ & $\begin{array}{l}30 \\
(15.54)\end{array}$ & $12(6.22)$ & $7(3.63)$ & $\begin{array}{l}22 \\
(11.40)\end{array}$ & $113(58.55)$ & $9(4.66)$ & & 3.96 & 1.51 \\
\hline 4 & $\begin{array}{l}\text {... were they encouraged to get to a specific } \\
\text { group or class to help them cope with their } \\
\text { chronic condition. }\end{array}$ & $\begin{array}{l}101 \\
(52.33)\end{array}$ & $11(5.70)$ & $11(5.70)$ & $7(3.63)$ & $13(6.74)$ & $\begin{array}{l}47 \\
(24.35)\end{array}$ & $3(1.55)$ & 1.74 & 1.14 \\
\hline 5 & $\begin{array}{l}\text {... were they helped to make a treatment } \\
\text { plan that they could carry out in their daily life. }\end{array}$ & $\begin{array}{l}70 \\
(36.34)\end{array}$ & $13(6.74)$ & $11(5.70)$ & $\begin{array}{l}20 \\
(10.36)\end{array}$ & 38 (19.7) & $\begin{array}{l}39 \\
(20.21)\end{array}$ & $2(1.04)$ & 2.63 & 1.52 \\
\hline 6 & $\begin{array}{l}\text {... were they helped to plan ahead so they } \\
\text { could take care of their condition even during } \\
\text { hard times. }\end{array}$ & 74 (38.3) & $18(9.33)$ & $11(5.70)$ & $19(9.84)$ & 35 (18.13) & $\begin{array}{l}34 \\
(17.62)\end{array}$ & $2(1.04)$ & 2.51 & 1.51 \\
\hline 7 & $\begin{array}{l}\text {... were they asked how much their chronic } \\
\text { disease affected their life. }\end{array}$ & $\begin{array}{l}51 \\
(26.42)\end{array}$ & $19(9.84)$ & $32(16.58)$ & $\begin{array}{l}27 \\
(13.99)\end{array}$ & $39(20.21)$ & $\begin{array}{l}25 \\
(12.95)\end{array}$ & & 2.91 & 1.45 \\
\hline 8 & $\begin{array}{l}\ldots \text { were they contacted after a visit to see } \\
\text { how things were going. }\end{array}$ & $\begin{array}{l}77 \\
(39.90)\end{array}$ & $28(14.50)$ & $29(15.0)$ & $16(8.3)$ & 30 (15.5) & $10(5.2)$ & $3(1.55)$ & 2.41 & 1.46 \\
\hline \multirow[t]{2}{*}{9} & $\begin{array}{l}\text {... were they told how much visits with other } \\
\text { types of doctors, like an eye doctor or }\end{array}$ & $\begin{array}{l}50 \\
(25.91)\end{array}$ & $13(6.74)$ & 20 (10.36) & $\begin{array}{l}25 \\
(12.95)\end{array}$ & 62 (32.12) & $\begin{array}{l}21 \\
(10.88)\end{array}$ & $2(1.04)$ & 3.21 & 1.58 \\
\hline & & $\begin{array}{l}\text { not at } \\
\text { all } \\
\text { satisfied } \\
\text { n (\%) }\end{array}$ & $\begin{array}{l}\text { generally } \\
\text { not } \\
\text { satisfied } \\
\text { n (\%) }\end{array}$ & $\begin{array}{l}\text { moderately } \\
\text { satisfied } \\
\text { n (\%) }\end{array}$ & $\begin{array}{l}\text { rather } \\
\text { satisfied } \\
\text { n (\%) }\end{array}$ & $\begin{array}{l}\text { completely } \\
\text { satisfied } \\
\text { n (\%) }\end{array}$ & $\begin{array}{l}\text { unable } \\
\text { to rate } \\
\mathrm{n}(\%)\end{array}$ & $\begin{array}{l}\text { Missing } \\
\mathrm{n}(\%)\end{array}$ & $\begin{array}{l}\text { Mean } \\
\text { rating }\end{array}$ & SD \\
\hline 10 & $\begin{array}{l}\text { Overall, how satisfied was the decedent with } \\
\text { the medical care received? }\end{array}$ & 15 (7.77) & $22(11.40)$ & $41(21.24)$ & $\begin{array}{l}65 \\
(33.68)\end{array}$ & $41(21.24)$ & $8(4.15)$ & $1(0.52)$ & 3.52 & 1.20 \\
\hline
\end{tabular}

${ }^{a}$ Key for of answer categories: almost never $=1$, generally not $=2$, sometimes $=3$, most of the time $=4$, almost always $=5$

with a diverse background in disease and treatment experiences. This allows us to gain a broad overview of the care process in the LYOL instead of looking at only one healthcare provider. Another strength is the inclusion of the answer category "unable to rate" in the instrument.
Including this item enabled participants to judge their ability and knowledge to serve as a proxy on the respective items, instead of being forced to provide guessed answers or producing missing values for which reasons are not traceable. It allowed for the prevention of random

Table 3 Results of factor analysis

\begin{tabular}{|c|c|c|c|}
\hline Item & How did your relative experience the care for their chronic illness during the last year of life? & $\begin{array}{l}\text { Factor } \\
\text { loading }\end{array}$ & $\begin{array}{l}\text { Kaiser-Meyer- } \\
\text { Olkin }\end{array}$ \\
\hline 1 & ... were they given choices about treatment to think about. & 0.66 & 0.92 \\
\hline 2 & ... were they satisfied that their care was well organized. & 0.62 & 0.91 \\
\hline 3 & ... were they given a copy of their treatment plan. & 0.58 & 0.93 \\
\hline 4 & $\begin{array}{l}\text {... were they encouraged to get to a specific group or class to help them cope with their chronic } \\
\text { condition. }\end{array}$ & 0.46 & 0.92 \\
\hline 5 & ... were they helped to make a treatment plan that they could carry out in their daily life. & 0.74 & 0.81 \\
\hline 6 & ... were they helped to plan ahead so they could take care of their condition even during hard times. & 0.82 & 0.81 \\
\hline 7 & ... were they asked how much their chronic disease affected their life. & 0.76 & 0.90 \\
\hline 8 & ... were they contacted after a visit to see how things were going. & 0.57 & 0.80 \\
\hline 9 & $\begin{array}{l}\ldots \text { were they told how much visits with other types of doctors, like an eye doctor or surgeon, helped } \\
\text { their treatment. }\end{array}$ & 0.75 & 0.87 \\
\hline
\end{tabular}




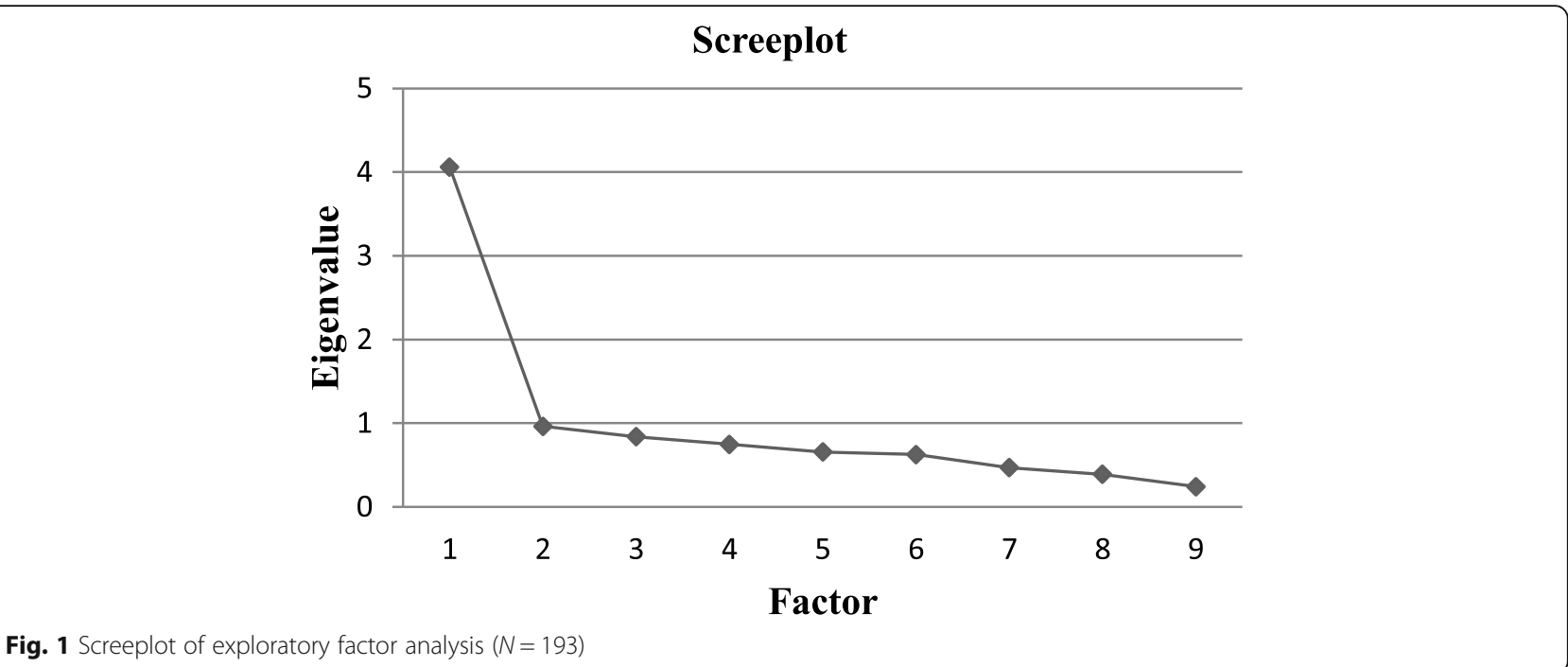

answer behavior and led to less than $1 \%$ missing values. The overall data quality can therefore be rated as high. Our study has several limitations. Firstly, participants were recruited mainly via self-selection, which might have biased the sample, as the informants that completed the survey were thusparticularly active and involved. However, direct recruitment via practice partners is assumed to minimize this potential bias. Second, this study's methods did not include a comparison with patient judgements of PCC. However, previous studies have already shown agreement in relation to quality of services [19], of which patient-centeredness can be one aspect. We are not able to assess any potential bias introduced by surveying proxies instead of selfreport answers.

\section{Conclusions}

The adapted PACIC-short form as a proxy version is suitable for eliciting the level of patient-centeredness in the care during the LYOL. The instrument might facilitate improvement of care during the LYOL by identifying areas in which patients or informants report low levels of patient-centeredness. The agreement between the patients' and the proxy informants' perceptions of patient-centeredness should be addressed in future studies, in samples where comparison between patient and proxy judgements might be possible.

\section{Supplementary Information}

The online version contains supplementary material available at https:/doi. org/10.1186/s12904-020-00687-x.

Additional file 1: Supplementary file 1. English Version: Patient Assessment of Chronic Illness Care Short Form for Proxies (PACIC-S9Proxy)

\section{Abbreviations}

IOM: Institute of Medicine; KMO: Kaiser-Meyer-Olkin; PACIC-S9-Proxy: Patient Assessment of Chronic IIIness Care- short form containing nine items for completion by proxy informants; PCC: Patient-centered care

\section{Acknowledgements}

The authors would like to thank all participants for their contribution to the study. This study was conducted within the Cologne Research and

Development Network (CoRe-Net) in cooperation with Christian Albus, Lena Ansmann, Frank Jessen, Ute Karbach, Ludwig Kuntz, Holger Pfaff, Ingrid Schubert, Frank Schulz-Nieswandt, and Nadine Scholten. The authors thank the Department of General Practice and Health Services Research, University Hospital Heidelberg, Heidelberg, Germany and Cristian Gugiu for their agreement to use and helpful comments in adapting the questionnaire.

The content of this manuscript has partly been presented at the 18th German Congress for Health Services Research, Berlin 2019.

\section{Authors' contributions}

RV, JS, CR and SS conceived the study. GD, NS and W elaborated on the specific procedures.GD and NS collected the data. W and AS conducted the data analysis. W drafted the manuscript. All the authors conducted critical revision of the manuscript and approved the final version.

\section{Funding}

This work was supported by the German Federal Ministry of Education and Research (grant no. 01GY1606). Open Access funding enabled and organized by Projekt DEAL.

\section{Availability of data and materials}

The datasets generated and/or analyzed during the current study are not publicly available due to data protection regulations, but are available from the corresponding author upon reasonable request and following application to CoRe-Net (Core-Net@uk-koeln.de).

Ethics approval and consent to participate Ethical approval for this study was obtained from the Ethics Committee of the Faculty of Medicine of Cologne University (no. 17-188). All participants provided written informed consent.

Consent for publication

Not applicable.

Competing interests

The authors report no competing interests. 


\section{Author details}

Institute for Health Economics and Clinical Epidemiology, Gleueler Straße 176-178, 50935 Cologne, Germany. ${ }^{2}$ Department of Palliative Medicine, Medical Faculty, University of Cologne, Cologne, Germany. Institute of Medical Sociology, Health Services Research, and Rehabilitation Science (IMVR), University of Cologne, Cologne, Germany. ${ }^{4}$ Heidelberg University of Education, Heidelberg, Germany. ${ }^{5}$ Center for Health Services Research Cologne (ZVFK), University of Cologne, Cologne, Germany. ${ }^{6}$ Center for Integrated Oncology Aachen Bonn Cologne Düsseldorf (CIO ABCD), University of Cologne, Cologne, Germany. ${ }^{7}$ Clinical Trials Center Cologne (ZKS), University of Cologne, Cologne, Germany.

Received: 28 April 2020 Accepted: 18 November 2020 Published online: 24 November 2020

\section{References}

1. Ni Chroinin D, Goldsbury DE, Beveridge A, Davidson PM, Girgis A, Ingham N, et al. Health-services utilisation amongst older persons during the last year of life: a population-based study. BMC Geriatr. 2018;18(1):317 PubMed PMID: 30572832. Pubmed Central PMCID: 6302397.

2. Hogan C, Lunney J, Gabel J, Lynn J. Medicare beneficiaries' costs of care in the last year of life. Health Aff. 2001;20(4):188-95 PubMed PMID: 11463076.

3. Lubitz JD, Riley GF. Trends in Medicare payments in the last year of life. N Engl J Med. 1993:328(15):1092-6. 8455667

4. Balint E. The possibilities of patient-centered medicine. J R Coll Gen Pract. 1969;17(82):269-76 PubMed PMID: 5770926. Pubmed Central PMCID: 2236 836.

5. Institute of Medicine (US). Crossing the Quality Chasm: A New Health System for the 21st Century. Washington (DC): Crossing the Quality Chasm: A New Health System for the 21st Century; 2001.

6. Koordinierungsstelle für Hospiz- und Palliativversorgung in Deutschland. Charta zur Betreuung schwerstkranker und sterbender Menschen in Deutschland 2019 [cited 2020 3rd March]. Available from: https://www. charta-zur-betreuung-sterbender.de/.

7. Scholl I, Zill JM, Härter M, Dirmaier J. An integrative model of patientcenteredness - a systematic review and concept analysis. PLoS One. 2014; 9(9):e107828 PubMed PMID: 25229640. Pubmed Central PMCID: 4168256.

8. Wagner EH, Austin BT, Davis C, Hindmarsh M, Schaefer J, Bonomi A. Improving chronic illness care: translating evidence into action. Health Aff. 2001;20(6):64-78 PubMed PMID: 11816692.

9. Langberg EM, Dyhr L, Davidsen AS. Development of the concept of patientcentredness - a systematic review. Patient Educ Couns. 2019;102(7):1228-36 PubMed PMID: 30846206.

10. Brickley B, Sladdin I, Williams LT, Morgan M, Ross A, Trigger K, et al. A new model of patient-centred care for general practitioners: results of an integrative review. Fam Pract. 2019:31 PubMed PMID: 31670759.

11. Hudon C, Fortin M, Haggerty J, Loignon C, Lambert M, Poitras ME. Patientcentered care in chronic disease management: a thematic analysis of the literature in family medicine. Patient Educ Couns. 2012;88(2):170-6 PubMed PMID: 22360841

12. Hudon C, Fortin M, Haggerty JL, Lambert M, Poitras ME. Measuring patients' perceptions of patient-centered care: a systematic review of tools for family medicine. Ann Fam Med. 2011;9(2):155-64 PubMed PMID: 21403143. Pubmed Central PMCID: 3056864

13. Kitson A, Marshall A, Bassett K, Zeitz K. What are the core elements of patient-centred care? A narrative review and synthesis of the literature from health policy, medicine and nursing. J Adv Nurs. 2013;69(1):4-15 PubMed PMID: 22709336

14. McCormack B. A conceptual framework for person-centred practice with older people. Int J Nurs Pract. 2003;9(3):202-9 PubMed PMID: 12801252.

15. Berntsen GKR, Dalbakk M, Hurley JS, Bergmo T, Solbakken B, Spansvoll L, et al. Person-centred, integrated and pro-active care for multi-morbid elderly with advanced care needs: a propensity score-matched controlled trial. BMC Health Serv Res. 2019:19(1):682 PubMed PMID: 31581947. Pubmed Central PMCID: 6777026

16. Brannstrom M, Boman K. Effects of person-centred and integrated chronic heart failure and palliative home care. PREFER: a randomized controlled study. Eur J Heart Fail. 2014;16(10):1142-51 PubMed PMID: 25159126.

17. Brazil K, Bainbridge D, Ploeg J, Krueger P, Taniguchi A, Marshall D. Family caregiver views on patient-centred care at the end of life. Scand I Caring Sci. 2012;26(3):513-8 PubMed PMID: 22117607.
18. Kogan AC, Wilber K, Mosqueda L. Person-centered Care for Older Adults with chronic conditions and functional impairment: a systematic literature review. J Am Geriatr Soc. 2016;64(1):e1-7 PubMed PMID: 26626408.

19. McPherson CJ, Addington-Hall JM. Judging the quality of care at the end of life: can proxies provide reliable information? Soc Sci Med. 2003;56(1):95109 PubMed PMID: 12435554.

20. de Silva D. Helping measure person-centred care- a review of evidence about commonly used approaches and tools used to help measure personcentred care the Health Foundation; 2014

21. Karbach U, Ansmann L, Scholten N, Pfaff H, fur die CoRe-Net A, Albus C, et al. [Report from an ongoing research project: The Cologne Research and Development Network (CoRe-Net) and the value-based approach to healthcare]. Z Evid Fortbild Qual Gesundhwes. 2018;130:21-26. PubMed PMID: 29269171. Bericht aus einem laufenden Forschungsprojekt: CoRe-Net, das Kolner Kompetenznetzwerk aus Versorgungspraxis und Versorgungsforschung, und der Value-based Healthcare-Ansatz.

22. Strupp J, Hanke G, Schippel N, Pfaff H, Karbach U, Rietz C, et al. Last year of life study Cologne (LYOL-C): protocol for a cross-sectional mixed methods study to examine care trajectories and transitions in the last year of life until death. BMJ Open. 2018;8(4):e021211 PubMed PMID: 29666139. Pubmed Central PMCID: 5905737

23. Hunt KJ, Shlomo N, Richardson A, J.M. A-H. VOICES Redesign and Testing to Inform a National End of Life Care Survey. Southampton: University of Southampton; 2011.

24. Goetz K, Freund T, Gensichen J, Miksch A, Szecsenyi J, Steinhaeuser J. Adaptation and psychometric properties of the PAClC short form. Am J Manag Care. 2012;18(2):e55-60 PubMed PMID: 22435885.

25. Gugiu C, Coryn CL, Applegate B. Structure and measurement properties of the patient assessment of chronic illness care instrument. J Eval Clin Pract. 2010;16(3):509-16. 20210824

26. Gugiu PC, Coryn C, Clark R, Kuehn A. Development and evaluation of the short version of the patient assessment of chronic illness care instrument. Chronic IIIn. 2009:5(4):268-76 PubMed PMID: 19933249.

27. Voltz R, Dust G, Schippel N, Hamacher S, Payne S, Scholten N, et al. Improving regional care in the last year of life by setting up a pragmatic evidence-based double loop Plan-Do-Study-Act cycle: Results from a crosssectional survey. (submitted bmjopen-2019-035988).

28. gesis Leibniz-Institut für Sozialwissenschaften. Design of Rating Scales in Questionnaires. GESIS Survey GuidelinesNatalja Meold Kathrin Bogner 18th September 2020. Available from: https://www.gesis.org/fileadmin/upload/ SDMwiki/MenoldBogner_Design_of_Rating_Scales_in_Questionnaires.pdf.

29. §31a of the Fifth Social Code Book - Statutory Health Insurance - (20 December 1988, BGBI. I S. 2477, 2482) Das Fünfte Buch Sozialgesetzbuch Gesetzliche Krankenversicherung - (Artikel 1 des Gesetzes vom 20. Dezember 1988, BGBI. I S. 2477, 2482), das zuletzt durch Artikel 5 des Gesetzes vom 22. März 2020 (BGBI. I S.604) geändert worden ist.

30. Lilleheie I, Debesay J, Bye A, Bergland A. Informal caregivers' views on the quality of healthcare services provided to older patients aged 80 or more in the hospital and 30 days after discharge. BMC Geriatr. 2020;20(1):97 PubMed PMID: 32164569. Pubmed Central PMCID: 7068939.

31. Glasgow RE, Wagner EH, Schaefer J, Mahoney LD, Reid RJ, Greene SM. Development and validation of the patient assessment of chronic illness care (PACIC). Med Care. 2005;43(5):436-44 PubMed PMID: 15838407.

32. Arditi C, Iglesias K, Peytremann-Bridevaux I. The use of the patient assessment of chronic illness care (PACIC) instrument in diabetes care: a systematic review and meta-analysis. Int J Qual Health Care. 2018;30(10): 743-50 PubMed PMID: 29733366.

\section{Publisher's Note}

Springer Nature remains neutral with regard to jurisdictional claims in published maps and institutional affiliations. 